\title{
Incidental findings on computed tomography coronary
}

\author{
angiography and its impact on respiratory services in a
}

\section{United Kingdom district general hospital [version 1; peer}

\section{review: 1 not approved]}

\author{
Bikash Gurung (iD), Finnian D. Lesser (iD), Ellis James (D), Kabali Nandakumar
}

Respiratory Department, Conquest Hospital, East Sussex Healthcare Trust, Hastings, Sussex, TN37 7RD, UK

V1 First published: 14 Aug 2020, 9:988

https://doi.org/10.12688/f1000research.25206.1

Latest published: 14 Aug 2020, 9:988

https://doi.org/10.12688/f1000research.25206.1

\section{Abstract}

Background: Computed tomography coronary angiography is used to assess for coronary artery disease but can also pick up non-cardiac pathology. Previous studies have assessed the frequency of noncardiac pathology. We investigated the non-cardiac findings and resulting follow up in a District General Hospital.

Methods: All computed tomography coronary angiography scans for 1 year were retrospectively collected. Basic demographics and the non-cardiac findings were recorded from electronic health records. The significant respiratory findings and the respiratory follow up of these non-cardiac findings were recorded.

Results: A total of 503 scans were carried out in one year. Of these scans, $24 \%$ had non cardiac findings present. Older patients were more likely to have non cardiac findings. The most common non cardiac findings were lung nodules, emphysema and hiatus hernias. Significant respiratory findings were present in 35 cases, which generated 24 episodes of respiratory follow up. Some patients who met criteria for follow up had not been referred.

Conclusions: Non cardiac findings are common on computed tomography coronary angiography and in our hospital these findings led to significant follow up in respiratory services.

\section{Keywords}

computed tomography coronary angiogram, incidental findings, lung nodule

\section{Open Peer Review \\ Approval Status $\mathrm{X}$ \\ 1 \\ version 1

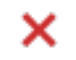 \\ 14 Aug 2020 \\ view \\ 1. Mohammad Kermani-Alghoraishi (iD), \\ Isfahan University of Medical Sciences, \\ Isfahan, Iran \\ Any reports and responses or comments on the article can be found at the end of the article.}


Corresponding author: Finnian D. Lesser (flesser@doctors.org.uk)

Author roles: Gurung B: Conceptualization, Data Curation, Writing - Original Draft Preparation, Writing - Review \& Editing; Lesser FD: Data Curation, Formal Analysis, Writing - Original Draft Preparation, Writing - Review \& Editing; James E: Data Curation, Writing Review \& Editing; Nandakumar K: Conceptualization, Writing - Review \& Editing

Competing interests: No competing interests were disclosed.

Grant information: The author(s) declared that no grants were involved in supporting this work.

Copyright: $\odot 2020$ Gurung B et al. This is an open access article distributed under the terms of the Creative Commons Attribution License, which permits unrestricted use, distribution, and reproduction in any medium, provided the original work is properly cited.

How to cite this article: Gurung B, Lesser FD, James E and Nandakumar K. Incidental findings on computed tomography coronary angiography and its impact on respiratory services in a United Kingdom district general hospital [version 1; peer review: 1 not approved] F1000Research 2020, 9:988 https://doi.org/10.12688/f1000research.25206.1

First published: 14 Aug 2020, 9:988 https://doi.org/10.12688/f1000research.25206.1 


\section{Introduction}

Computed tomography coronary angiography (CTCA) is used to assess for coronary artery disease in patients with chest pain and in preprocedural planning. In the United Kingdom the National Institute for Health and Care Excellence (NICE) guidelines 2016 have recommended CTCA as the first-choice imaging modality in patients with chest pain ${ }^{1}$. Aside from imaging the coronary arteries, CTCA will also image surrounding structures and can pick up non-cardiac findings (NCF). Some of the NCF will need follow up and further investigation, which has cost and service delivery implications ${ }^{2}$.

The NCF of CTCA have been previously investigated in prospective and retrospective cohort studies with greatly varying proportions of incidental finding in $\mathrm{scans}^{2-15}$. A systematic review of all forms of cardiac CT found NCF in 7\%-100\% of studies included $^{16}$. The most common findings in previous studies have been respiratory, in particular lung nodules.

The British thoracic society guidelines and the Fleischner society have guidelines of the follow up of lung nodules ${ }^{17,18}$.

In this study of a district general hospital we assessed the frequency of NCF on CTCA, their significance and the follow up requested. The hospital provides secondary care services for cardiology, respiratory, gastroenterology and orthopaedics among other services.

\section{Methods}

Ethical approval for data collection and analysis was received from our institution's clinical effectiveness team and all patient data has been anonymised. As the data was retrospectively collected and did not affect the included patients care no further ethical approval was required.

All CTCA performed for one year (2018) were collected retrospectively. Data were reviewed on electronic health records with demographics of patient's age and sex recorded in an Excel spreadsheet. The CTCA's had been performed on a Toshiba Acquillion One using the standard protocol and the images reported by consultant radiologists. NCF were recorded and divided by speciality. Patients with respiratory NCF had their notes reviewed for significance of findings, initial referral and follow up.Findings were assessed as significant if they required further investigation, follow up or treatment. For lung nodules significance was determined by whether they met criteria for further follow up according to British Thoracic Society Guidelines $^{18}$.If a significant finding had not been followed up the primary careprovider for the patient involved was informed.

\section{Statistical analysis}

Statistical analysis was performed using Jamovi (version 1.2.22) ${ }^{19}$. Normally distributed data are presented as means and standard deviations. Statistical significance was assessed by t-test or chi squared test, as appropriate. A p value $<0.05$ was deemed significant.

\section{Results}

A total of 503 CTCA were requested in 12 months with nearly all being requested by cardiology and 3 by primary care. There were 284 scans on females and 219 scans on males. The average age of the patients was 60 .

NCF were identified in $120(24 \%)$. NCF were more frequent in older patients with statistical significance. For gender there was no statistically significant difference in likelihood to have NCF (Table 1). Details of all CTCA and resultant NCF are available as Underlying data ${ }^{20}$.

Of the NCF identified, 95 were respiratory with the majority being lung nodules (Table 2). The respiratory NCF were judged to be significant in 35 cases ( $7 \%$ of total scans). Other NCF were found in gastroenterology, orthopaedic and endocrine specialties which we did not assess for significance.

Onward referral for imaging (all CT Chest) was requested in 18 patients with results followed up by the respiratory team (Table 3). In addition to this, 5 patients were reviewed in the respiratory clinic without further imaging and 1 in a multidisciplinary team meeting.

There were 16 patients who had significant respiratory findings not referred for secondary care follow up, of these 9 were emphysema or parenchymal changes, 5 were nodules and 1 was a pleural effusion.

\section{Discussion}

$\mathrm{NCF}$ on CTCA are common, but the majority of these are not significant. If the use of CTCA increases, this will lead to significant downstream effects on other specialties, especially respiratory. In our hospital, one year's worth of CTCA led to 24 respiratory follow ups in terms of imaging and clinic appointments.

Table 1. The baseline characteristics of patients who had CTCA split by presence of non-cardiac findings.

\begin{tabular}{|l|l|l|l|}
\hline Variable & Non-cardiac findings present & Non-cardiac findings absent & p value \\
\hline Number of patients (\%) & $120(24 \%)$ & $382(76 \%)$ & \\
\hline Age (years) mean \pm SD & $63 \pm 12$ & $59 \pm 12$ & 0.002 \\
\hline Male, $\mathrm{n}(\%)$ & $51(42 \%)$ & $167(44 \%)$ & 0.745 \\
\hline
\end{tabular}




\begin{tabular}{|c|c|c|}
\hline System & Finding & $\begin{array}{l}\text { Frequency } \\
\text { (significant) }\end{array}$ \\
\hline \multirow[t]{14}{*}{ Respiratory } & Nodule & $36(19)$ \\
\hline & Emphysema or parenchymal changes & $15(9)$ \\
\hline & Atelectasis & $14(0)$ \\
\hline & Granuloma & $11(0)$ \\
\hline & Old inflammatory changes & $6(0)$ \\
\hline & Bronchiectasis & $3(0)$ \\
\hline & Pneumonitis & $3(1)$ \\
\hline & Lung Mass & $1(1)$ \\
\hline & Raised Hemidiapragm & $1(1)$ \\
\hline & Fibrosis & $1(1)$ \\
\hline & Pulmonary artery dilatation & $1(1)$ \\
\hline & Pleural thickening & $1(1)$ \\
\hline & Pleural effusions & $1(1)$ \\
\hline & Mucous plugging & $1(0)$ \\
\hline Gastrointestinal & Hiatus Hernia & 10 \\
\hline \multirow[t]{2}{*}{ Orthopaedic } & Spinal degeneration & 8 \\
\hline & Sternal abnormality & 2 \\
\hline Other Findings with $n$ of 1 & $\begin{array}{l}\text { Adrenal Adenoma, Liver Hemangioma, Liver Steatosis, Oesophageal } \\
\text { malignancy, Pancreatic duct dilatation }\end{array}$ & 1 \\
\hline
\end{tabular}

\section{Table 3. The frequency of initial follow up of respiratory non-cardiac findings and not followed up significant findings.}

\begin{tabular}{|l|l|l|l|l|}
\hline Finding & $\begin{array}{l}\text { Further imaging and } \\
\text { referral }\end{array}$ & $\begin{array}{l}\text { Clinic } \\
\text { review }\end{array}$ & $\begin{array}{l}\text { Multidisciplinary } \\
\text { team meeting }\end{array}$ & $\begin{array}{l}\text { Not } \\
\text { followed up }\end{array}$ \\
\hline Nodule & 12 & 1 & 1 & 5 \\
\hline $\begin{array}{c}\text { Emphysema or } \\
\text { parenchymal changes }\end{array}$ & & & & 9 \\
\hline $\begin{array}{c}\text { Pneumonitis } \\
\text { Others }\end{array}$ & 6 & 1 & & \\
\hline
\end{tabular}

Even non-significant findings may lead to referrals and investigations if the ordering clinician is unsure of the current guidelines.

Other similar studies show a large variability in proportion of NCF in CTCA, likely due to variability in study populations, equipment and protocols used. Our results are similar to the most recent large UK dataset from the SCOT HEART trial with NCF more frequent as age increases and the most common findings being lung nodules, emphysema and hiatus hernia ${ }^{2}$. These additional data from a single district general hospital should inform other healthcare providers of possible service provision consequences from the use of CTCA.

We identified several patients who would have met criteria for follow up with lung nodules but did not receive this follow up. For some of the NCF such as emphysema and hiatus hernia the patients primary care practitioner will be the correct route of follow up and so they should be informed of the result. As these patients are all symptomatic enough to warrant a CTCA optimising their treatment for NCF seems prudent particularly as these may be the underlying cause of the symptoms. Not correctly 
following up lung nodules can have significant implications for the patient and in our data set some patients were not followed up according to guidelines.

Cardiologists may not be familiar with the follow up of NCF and so should be cautious when interpreting scan reports. As $\mathrm{NCF}$ are common in CTCA a standardised method of reviewing scans and referring findings could be considered with the aim to reduce unnecessary follow up requests and missed significant findings.

\section{Conclusion}

NCF are frequent on CTCA and will lead to downstream follow up which will have implications in terms of cost, service provision and patient's time.

\section{Data availability}

Underlying data

Figshare: Data from: Incidental findings on computed tomography coronary angiography and its impact on respiratory services in a United Kingdom district general hospital. https://doi. org/10.6084/m9.figshare.12600056.v2 ${ }^{20}$.

This project contains details of each computed tomography coronary angiography procedure performed, including a description of the non-cardiac findings, where applicable. To anonymise the data patient age and date of birth is not included.

Data are available under the terms of the Creative Commons Attribution 4.0 International license (CC-BY 4.0).
1. Overview I Recent-onset chest pain of suspected cardiac origin: assessment and diagnosis I Guidance I NICE. NICE; [cited 2020 Jun 18]. Reference Source

2. Williams MC, Hunter A, Shah ASV, et al.: Impact of noncardiac findings in patients undergoing CT coronary angiography: a substudy of the Scottish computed tomography of the heart (SCOT-HEART) trial. Eur Radiol. 2018; 28(6): 2639-46.

PubMed Abstract | Publisher Full Text | Free Full Text

3. Haller S, Kaiser C, Buser P, et al.: Coronary Artery Imaging with ContrastEnhanced MDCT: Extracardiac Findings. AJR Am J Roentgenol. 2006; 187(1): 105-10.

PubMed Abstract | Publisher Full Text

4. Karius $\mathrm{P}$, Lembcke A, Sokolowski FC, et al.: Extracardiac findings on coronary computed tomography angiography in patients without significant coronary artery disease. Eur Radiol. 2019; 29(4): 1714-23. PubMed Abstract | Publisher Full Text

5. Johnson KM, Dennis JM, Dowe DA: Extracardiac findings on coronary CT angiograms: Limited versus complete image review. AJR Am J Roentgenol. 2010; 195(1): 143-8.

PubMed Abstract | Publisher Full Text

6. Kawano $Y$, Tamura A, Goto $Y$, et al: Incidental detection of cancers and other non-cardiac abnormalities on coronary multislice computed tomography. $A m \mathrm{~J}$ Cardiol. 2007; 99(11): 1608-9.

PubMed Abstract | Publisher Full Text

7. Boldeanu I, Perreault Bishop J, Nepveu S, et al.: Incidental findings in CT imaging of coronary artery bypass grafts: results from a Canadian multicenter prospective cohort. BMC Res Notes. 2018; 11(1): 72 PubMed Abstract | Publisher Full Text | Free Full Text

8. Lazoura O, Vassiou K, Kanavou T, et al:: Incidental Non-Cardiac Findings of a Coronary Angiography with a 128-Slice Multi-Detector CT Scanner: Should We Only Concentrate on the Heart? Korean J Radiol. 2010; 11(1): 60-8. PubMed Abstract | Publisher Full Text | Free Full Text

9. Onuma $\mathrm{Y}$, Tanabe K, Nakazawa G, et al:: Noncardiac Findings in Cardiac Imaging With Multidetector Computed Tomography. J Am Coll Cardiol. 2006; 48(2): 402-6.

PubMed Abstract | Publisher Full Text

10. Machaalany J, Yam Y, Ruddy TD, et al:: Potential clinical and economic consequences of noncardiac incidental findings on cardiac computed tomography. J Am Coll Cardiol. 2009; 54(16): 1533-41.

PubMed Abstract | Publisher Full Text
11. Cho JH, Park JS, Shin DG, et al.: Prevalence of extracardiac findings in the evaluation of ischemic heart disease by multidetector computed tomography. J Geriatr Cardiol. 2013; 10(3): 242-6. PubMed Abstract | Publisher Full Text | Free Full Text

12. Chia PL, Kaw G, Wansaicheong G, et al:: Prevalence of non-cardiac findings in a large series of patients undergoing cardiac multi-detector computed tomography scans. Int J Cardiovasc Imaging. 2009; 25(5): 537-43. PublMed Abstract | Publisher Full Text

13. Law YM, Huang J, Chen K, et al.: Prevalence of significant extracoronary findings on multislice $\mathrm{CT}$ coronary angiography examinations and coronary artery calcium scoring examinations. J Med Imaging Radiat Oncol. 2008; 52(1): 49-56.

PubMed Abstract | Publisher Full Text

14. Gil BN, Ran K, Tamar G, et al.: Prevalence of Significant Noncardiac Findings on Coronary Multidetector Computed Tomography Angiography in Asymptomatic Patients. J Comput Assist Tomogr. 2007; 31(1): 1-4. PubMed Abstract | Publisher Full Text

15. Lehman SJ, Abbara S, Cury RC, et al:: Significance of cardiac computed tomography incidental findings in acute chest pain. Am J Med. 2009; 122(6): 543-9.

PubMed Abstract | Publisher Full Text

16. Kay FU, Canan A, Abbara S: Common Incidental Findings on Cardiac CT: a Systematic Review. Curr Cardiovasc Imaging Rep. 2019; 12(6): 21. Publisher Full Text

17. MacMahon H, Naidich DP, Goo JM, et al:: Guidelines for Management of Incidental Pulmonary Nodules Detected on CT Images: From the Fleischner Society 2017. Radiology. 2017; 284(1): 228-43. PubMed Abstract | Publisher Full Text

18. Callister MEJ, Baldwin DR, Akram AR, et al:: British Thoracic Society guidelines for the investigation and management of pulmonary nodules. Thorax. 2015; 70 Suppl 2: ii1-ii54. PubMed Abstract | Publisher Full Text

19. The jamovi project. Jamovi. 2020 Reference Source

20. Gurung B, Lesser FD, James E, et al.: Data from: Incidental findings on computed tomography coronary angiography and its impact on respiratory services in a United Kingdom district general hospital. figshare. Dataset. 2020. http://www.doi.org/10.6084/m9.figshare.12600056.v2 


\section{Open Peer Review}

\section{Current Peer Review Status:}

\section{Version 1}

Reviewer Report 08 February 2022

https://doi.org/10.5256/f1000research.27816.r96899

(C) 2022 Kermani-Alghoraishi M. This is an open access peer review report distributed under the terms of the Creative Commons Attribution License, which permits unrestricted use, distribution, and reproduction in any medium, provided the original work is properly cited.

\section{Mohammad Kermani-Alghoraishi}

Interventional Cardiology Research Center, Cardiovascular Research Institute, Isfahan University of Medical Sciences, Isfahan, Iran

I reviewed this paper regarding to incidental finding in patients underwent CCTA.

This is good idea, but the methodology and statistics are weak. Also, this title has not enough novelty and it is practical locally.

One of the most important limitations of this study is that CCTA technical approach is different with lung and mediastinal CT approaches and it can not conclude about the lung diseases accurately.

Also, it was better that authors analysis the relation between the incidental findings with CCTA results as well as demographic data.

Is the work clearly and accurately presented and does it cite the current literature? Partly

Is the study design appropriate and is the work technically sound? Partly

Are sufficient details of methods and analysis provided to allow replication by others? No

If applicable, is the statistical analysis and its interpretation appropriate? No

Are all the source data underlying the results available to ensure full reproducibility? Partly 
Are the conclusions drawn adequately supported by the results?

Partly

Competing Interests: No competing interests were disclosed.

Reviewer Expertise: Cardiovascular Medicine

I confirm that I have read this submission and believe that I have an appropriate level of expertise to state that I do not consider it to be of an acceptable scientific standard, for reasons outlined above.

The benefits of publishing with F1000Research:

- Your article is published within days, with no editorial bias

- You can publish traditional articles, null/negative results, case reports, data notes and more

- The peer review process is transparent and collaborative

- Your article is indexed in PubMed after passing peer review

- Dedicated customer support at every stage

For pre-submission enquiries, contact research@f1000.com

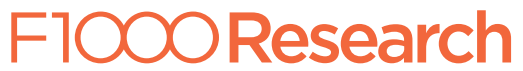

